\title{
Editorial June 2010
}

\author{
Mathias Gautel
}

Published online: 15 July 2010

(C) Springer Science+Business Media B.V. 2010

Following a successful term as Executive Editor of the Journal of Muscle Research and Cell Motility, Prof. Christopher Ashley has stepped down from the position of managing editor as per December 2009. This role has now rotated to Prof. Mathias Gautel, Kings' College London. Chris Ashley's term saw the JMRCM impact factor increase to 2.000 in 2008, with an increasingly global authorship and readership. We are very grateful to Chris for his leadership and dedication during sometimes difficult times. The editors foresee a bright future ahead for the JMRCM and look forward to new developments.

There is a general feeling within the muscle research community that there lacks an adequate forum for rapid publication. Consequently, JMRCM will soon introduce a new rapid publication stream. Under this scheme, short and essentially complete reports that require no major revisions will be fast-tracked through the publication process and will appear online as full publications (fully citable by DOI number) on SpringerLink as well as in databases such as PubMed within weeks of acceptance.
The Editorial team will also strive to reduce the JMRCM's review times in order to speed up the decision process and serve our authors better. We are optimistic that both developments will make the Journal a more attractive place to publish high-quality work, but we are humbly aware that we will continue to rely heavily on the support from our dedicated reviewers, whose contributions cannot be valued enough.

The future will also see a gradual expansion of the JMRCM Editorial Board to reflect more widely the scientific and geographic scope of Muscle and Cell Motility research. We will furthermore implement changes in the design of the Journal and the scope of reviews, where we will invite more participation from our authors.

We hope our readers, authors and reviewers will support the transformation of the Journal towards a more rapid and inclusive publication for the muscle and cell motility community.

The Editors of The Journal of Muscle Research and Cell Motility.
M. Gautel ( $₫)$

BHF Professor of Molecular Cardiology, Cardiovascular Division and Randall Division for Cell and Molecular Biophysics, King's College London, London SE1 1UL, UK e-mail: mathias.gautel@kcl.ac.uk 